\title{
Introduction to Special Issue on Symmetry in Mechanical Engineering
}

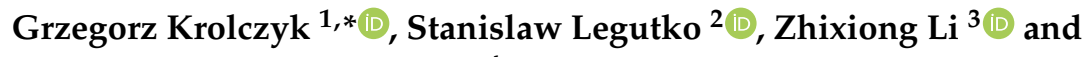 \\ Jose Alfonso Antonino Daviu 4 \\ 1 Faculty of Mechanical Engineering, Opole University of Technology, 76 Proszkowska St., \\ 45-758 Opole, Poland \\ 2 Faculty of Mechanical Engineering and Management, Poznan University of Technology, 3 Piotrowo Street, \\ 60-965 Poznan, Poland; stanislaw.legutko@put.poznan.pl \\ 3 School of Mechanical, Materials, Mechatronic and Biomedical Engineering, University of Wollongong, \\ Wollongong, NSW 2522, Australia; zhixiong.li@ieee.org \\ 4 Instituto Tecnológico de la Energía, Universitat Politècnica de València (UPV), Camino de Vera s/n, \\ 46022 Valencia, Spain; joanda@die.upv.es \\ * Correspondence: g.krolczyk@po.opole.pl
}

Received: 22 January 2020; Accepted: 22 January 2020; Published: 5 February 2020

\section{Introduction}

Recent advancements in mechanical engineering are an essential topic for discussion. The topics relating to mechanical engineering include the following: measurements of signals of shafts, springs, belts, bearings, gears, rotors, machine elements, vibration analysis, acoustic analysis, fault diagnosis, construction, analysis of machine operation, analysis of smart-material systems, integrated systems, stresses, analysis of deformations, analysis of mechanical properties, signal processing of mechanical systems, and rotor dynamics. Mechanical engineering deals with solid and fluid mechanics, rotation, movements, materials, and thermodynamics.

\section{The Content}

This Special Issue, with 15 published articles, presents the topic "Symmetry in Mechanical Engineering". The presented topic is interesting. It is categorized into eight different sections:

- deformation;

- $\quad$ stresses;

- mechanical properties;

- tribology;

- thermodynamic;

- measurement;

- fault diagnosis;

- machine;

The authors of the first paper analysed the self-excited vibration of a thin spur gear caused by the initial transverse vibration [1]. The article [2] described a new technique to identify sectional deformation modes of the doubly symmetric thin-walled cross-section. The matching model of the dual mass flywheel and the power transmission by integration of the sensitivity analysis method was presented in the paper [3]. In the paper [4], the authors presented an approach for the active control of structural vibration. The authors of the paper [5] presented an approach to the correction of optical measurement results of fertilizer particles. Fault diagnosis of the rolling bearing using vibration 
signals was presented in [6]. A study of the effect of medium viscosity on breakage parameters for wet grinding was presented in [7]. The monitoring method for the wear state of a tool using a convolutional bidirectional LSTM model was shown in the article [8]. The use of structural symmetries of a U12 engine using vibration analysis was presented in [9].

The Special Issue contains other interesting papers about mechanical engineering. The presented solutions, methods, and approaches can be improved and used in the future. Moreover, mechanical engineering is essential for fault diagnosis of machines [10-22] and the analysis of temperature [23-25]. The mechanical properties of materials are also investigated in the literature [26-28]. Acoustic analysis is also profitable for the analysis of the power transformer and detection of defects in on-load tap-changers $[29,30]$. Acoustically induced cavitation bubbles in insulating oil are also presented in the literature [31].

\section{Summary}

The development of techniques and methods related to mechanical engineering is growing every month. The described articles have contribution to mechanical engineering. The proposed research can find applications in factories, oil refineries, and mines. It is essential to develop new improved methods, techniques and devices related to mechanical engineering.

Author Contributions: All the authors contributed equally to the conception of the idea, implementing and analyzing the experimental results, and writing the manuscript. All authors have read and agreed to the published version of the manuscript.

Acknowledgments: The Guest Editors would like to thank all authors, reviewers and the editorial board of the MDPI Symmetry journal for their valuable contributions to this Special Issue.

Conflicts of Interest: The author declares no conflict of interest.

\section{References}

1. Wang, Y.; Ye, H.; Yang, L.; Tian, A. On the Existence of Self-Excited Vibration in Thin Spur Gears: A Theoretical Model for the Estimation of Damping by the Energy Method. Symmetry 2018, 10, 664. [CrossRef]

2. Zhang, L.; Ji, A.; Zhu, W.; Peng, L. On the Identification of Sectional Deformation Modes of Thin-Walled Structures with Doubly Symmetric Cross-Sections Based on the Shell-Like Deformation. Symmetry 2018, 10, 759. [CrossRef]

3. Chen, L.; Zhang, X.; Yan, Z.; Zeng, R. Matching Model of Dual Mass Flywheel and Power Transmission Based on the Structural Sensitivity Analysis Method. Symmetry 2019, 11, 187. [CrossRef]

4. Bai, L.; Feng, Y.-W.; Li, N.; Xue, X.-F.; Cao, Y. Data-Driven Adaptive Iterative Learning Method for Active Vibration Control Based on Imprecise Probability. Symmetry 2019, 11, 746. [CrossRef]

5. Laucka, A.; Adaskeviciute, V.; Andriukaitis, D. Research of the Equipment Self-Calibration Methods for Different Shape Fertilizers Particles Distribution by Size Using Image Processing Measurement Method. Symmetry 2019, 11, 838. [CrossRef]

6. Lu, L.; Yuan, Y.; Wang, H.; Zhao, X.; Zheng, J. A New Second-Order Tristable Stochastic Resonance Method for Fault Diagnosis. Symmetry 2019, 11, 965. [CrossRef]

7. Osorio, A.M.; Bustamante, M.O.; Restrepo, G.M.; Lopez, M.M.M.; Menendez-Aguado, J.M. A Study of the Effect of Medium Viscosity on Breakage Parameters for Wet Grinding. Symmetry 2019, 11, 1202. [CrossRef]

8. Chen, Q.; Xie, Q.; Yuan, Q.; Huang, H.; Li, Y. Research on a Real-Time Monitoring Method for the Wear State of a Tool Based on a Convolutional Bidirectional LSTM Model. Symmetry 2019, 11, 1233. [CrossRef]

9. Mihalcica, M.; Vlase, S.; Paun, M. The Use of Structural Symmetries of a U12 Engine in the Vibration Analysis of a Transmission. Symmetry 2019, 11, 1296. [CrossRef]

10. Irfan, M. A Novel Non-intrusive Method to Diagnose Bearings Surface Roughness Faults in Induction Motors. J. Fail. Anal. Prev. 2018, 18, 145-152. [CrossRef]

11. Caesarendra, W.; Tjahjowidodo, T.; Kosasih, B.; Tieu, A.K. Integrated Condition Monitoring and Prognosis Method for Incipient Defect Detection and Remaining Life Prediction of Low Speed Slew Bearings. Machines 2017, 5, 11. [CrossRef] 
12. Glowacz, A. Recognition of acoustic signals of induction motor using FFT, SMOFS-10 and LSVM. Eksploat. I Niezawodn. Maint. Reliab. 2015, 17, 569-574. [CrossRef]

13. Glowacz, A. Recognition of Acoustic Signals of Loaded Synchronous Motor Using FFT, MSAF-5 and LSVM. Arch. Acoust. 2015, 40, 197-203. [CrossRef]

14. Sikora, M.; Szczyrba, K.; Wrobel, L.; Michalak, M. Monitoring and maintenance of a gantry based on a wireless system for measurement and analysis of the vibration level. Eksploat. I Niezawodn. Maint. Reliab. 2019, 21, 341-350. [CrossRef]

15. Glowacz, A.; Glowacz, Z. Recognition of rotor damages in a DC motor using acoustic signals. Bull. Pol. Acad. Sci. Tech. Sci. 2017, 65, 187-194. [CrossRef]

16. Caesarendra, W.; Wijaya, T.; Tjahjowidodo, T.; Pappachan, B.K.; Wee, A.; Roslan, M.I. Adaptive neuro-fuzzy inference system for deburring stage classification and prediction for indirect quality monitoring. Appl. Soft Comput. 2018, 72, 565-578. [CrossRef]

17. Irfan, M.; Saad, N.; Ibrahim, R.; Asirvadam, V.S.; Alwadie, A. Analysis of distributed faults in inner and outer race of bearing via Park vector analysis method. Neural Comput. Appl. 2019, 31, 683-691. [CrossRef]

18. Glowacz, A.; Glowacz, W.; Kozik, J.; Piech, K.; Gutten, M.; Caesarendra, W.; Liu, H.; Brumercik, F.; Irfan, M.; Khan, Z.F. Detection of Deterioration of Three-phase Induction Motor using Vibration Signals. Meas. Sci. Rev. 2019, 19, 241-249. [CrossRef]

19. Glowacz, A. Acoustic fault analysis of three commutator motors. Mech. Syst. Signal Process. 2019, 133, 106226. [CrossRef]

20. Stief, A.; Ottewill, J.R.; Baranowski, J.; Orkisz, M. A PCA and Two-Stage Bayesian Sensor Fusion Approach for Diagnosing Electrical and Mechanical Faults in Induction Motors. IEEE Trans. Ind. Electron. 2019, 66, 9510-9520. [CrossRef]

21. Xi, W.K.; Li, Z.X.; Tian, Z.; Duan, Z.H. A feature extraction and visualization method for fault detection of marine diesel engines. Measurement 2018, 116, 429-437. [CrossRef]

22. Li, Z.X.; Wu, D.Z.; Hu, C.; Terpenny, J. An ensemble learning-based prognostic approach with degradation-dependent weights for remaining useful life prediction. Reliab. Eng. Syst. Saf. 2019, 184, 110-122. [CrossRef]

23. Chen, J.L.; Su, J.; Kochan, O.; Levkiv, M. Metrological Software Test for Simulating the Method of Determining the Thermocouple Error in Situ during Operation. Meas. Sci. Rev. 2018, 18, 52-58. [CrossRef]

24. Wang, J.F.; Kochan, O.; Przystupa, K.; Su, J. Information-measuring System to Study the Thermocouple with Controlled Temperature Field. Meas. Sci. Rev. 2019, 19, 161-169. [CrossRef]

25. Maruda, R.W.; Feldshtein, E.; Legutko, S.; Krolczyk, G.M. Analysis of Contact Phenomena and Heat Exchange in the Cutting Zone Under Minimum Quantity Cooling Lubrication conditions. Arab. J. Sci. Eng. 2016, 41, 661-668. [CrossRef]

26. Krolczyk, G.; Legutko, S.; Stoic, A. Influence of cutting parameters and conditions onto surface hardness of Duplex Stainless Steel after turning process. Teh. Vjesn. Tech. Gaz. 2013, 20, 1077-1080.

27. Kumar, R.; Chattopadhyaya, S.; Hloch, S.; Krolczyk, G.; Legutko, S. Wear characteristics and defects analysis of friction stir welded joint of aluminium alloy 6061-t6. Eksploat. I Niezawodn. Maint. Reliab. 2016, 18, 128-135. [CrossRef]

28. Krolczyk, J.B.; Krolczyk, G.M.; Legutko, S.; Napiorkowski, J.; Hloch, S.; Foltys, J.; Tama, E. Material flow optimization-A case study in automotive industry. Teh. Vjesn. Tech. Gaz. 2015, 22, 1447-1456.

29. Borucki, S.; Cichon, A.; Boczar, T.; Fracz, P. The Analysis of the Impact Point of the Power Transformer Core of Torsional Load on the Measured Parameters of the Vibroacoustics Signals. In Proceedings of the 2012 IEEE International Symposium on Electrical Insulation (ISEI), San Juan, PR, USA, 10-13 June 2012; pp. 175-178.

30. Cichon, A.; Fracz, P.; Boczar, T.; Zmarzly, D. Detection of Defects in On-Load Tap-Changers Using Acoustic Emission Method. In Proceedings of the 2012 IEEE International Symposium on Electrical Insulation (ISEI), San Juan, PR, USA, 10-13 June 2012; pp. 184-188.

31. Szmechta, M.; Zmarzly, D.; Boczar, T.; Lorenc, M. Acoustic Spectra of Ultrasound Induced Cavitations in Insulating Oils. Acta Phys. Pol. A 2008, 114, A231-A238. [CrossRef]

(C) 2020 by the authors. Licensee MDPI, Basel, Switzerland. This article is an open access article distributed under the terms and conditions of the Creative Commons Attribution (CC BY) license (http://creativecommons.org/licenses/by/4.0/). 